\title{
РОЛЬ ИПОТЕЧНОГО ЖИЛИЩНОГО КРЕДИТОВАНИЯ В ОБЕСПЕЧЕНИИ УСТОЙЧИВОГО РАЗВИТИЯ НАЦИОНАЛЬНОЙ ЭКОНОМИКИ
}

\author{
(c) 2020 Иванова Дарья Геннадьевна \\ кандидат экономических наук, доцент кафедры «Мировой экономики» \\ Ростовский государственный экономический университет, Россия, Ростов-на-Дону \\ E-mail: ivanova753@yandex.ru
}

Статья посвящена исследованию роли ипотечного жилищного кредитования в контексте концепции устойчивого развития. Рассмотрены принципы ипотечного рынка, а также проведен анализ инструментов его регулирования. Особое внимание уделено программам ипотечного жилищного кредитования, реализуемым в период пандемии COVID-19.

Ключевые слова: ипотечное жилищное кредитование, устойчивое развитие, принципы ипотечного рынка, инструменты регулирования, программы ипотечного жилищного кредитования.

В условиях современных глобальных вызовов проблема обеспечения устойчивого развития национальной экономики, одним из факторов которого выступает ипотечное кредитование, представляется особенно актуальной.

Обеспеченность населения жильем является частью социально-экономической политики каждого развитого демократического государства. Решение данной задачи обуславливает необходимость наличия у населения собственных накоплений денежных средств (для единовременного внесения первоначального взноса за приобретаемый объект жилой недвижимости), а также достаточных совокупных доходов заемщика, дающих возможность получения ипотечного жилищного кредита.

В современных реалиях государственная социально-экономическая политика должна быть направлена на стимулирование роста накоплений собственных денежных средств населения, на создание условий для привлечения этих сбережений и эффективного их инвестирования в жилищную сферу.

Российская Федерация реализует двухуровневую модель ипотечного жилищного кредитования. Рефинансирование ипотечных жилищных кредитов на государственном уровне поручено Агентству по ипотечному жилищному кредитованию, учрежденному Постановлением Правительства от 26.08.1996 № 1010 (далее - АО «АИЖК», с марта 2018 года - АО «Дом.рф»). Единый институт развития в жилищной сфере АО «Дом.рф», 100\% акций которого принадлежит государству, реализует государственные инициативы, направленные на повышение качества и доступности жилья для граждан [1].
В Российской Федерации создана соответствующая правовая основа ипотечного жилищного кредитования, основанная на нормах Конституции РФ, Гражданского кодекса Российской Федерации (далее - ГК РФ, § 3 гл. 23); Федерального закона от 16.02.1998 № 102-ФЗ «Об ипотеке (залоге недвижимости)» (далее - ФЗ № 102-ФЗ), федерального закона от 11.11.2003 № 152-Ф3 «Об ипотечных ценных бумагах» (далее - ФЗ № 152-Ф3). К отношениям в сфере ипотечного жилищного кредитования применяются, согласно п. 4 ст. 334 ГК РФ, нормы вещного права, общие положения о залоге; также нормы законов о финансовых рынках, о банковской деятельности, о долевом строительстве и др. Важное значение имеют нормы Жилищного кодекса РФ (далее - ЖК РФ); федеральных законов от 13.07.2015 № 122-Ф3 «О государственной регистрации недвижимости» (далее - ФЗ № 218-ФЗ); от 30.12.2004 г. № 218-ФЗ «О кредитных историях» (далее - ФЗ № 218-Ф3); законы субъектов Федерации, подзаконные акты разного уровня.

Государство, принимая различные меры по поддержке ипотечного жилищного кредитования, одновременно решает несколько задач, важнейшими из которых являются поддержка населения в обеспечении жильем и поддержка строительной отрасли, как одного из драйверов экономики. Банк России снижает ключевую ставку, снижение ставок по ипотечным кредитам ведет к росту покупательского спроса и объема выдачи кредитов. Однако отметим, что, хотя уменьшение процентов и выгодные условия ипотечного жилищного кредитования, предлагаемые банками, стимулируют ипотечный рынок и продажи недвижимости, основную роль в 
развитии ипотечного жилищного кредитования играет платежеспособность населения и устойчивость экономики, как в целом в Российской Федерации, так и в региональном аспекте.

Лидерами по выдаче ипотечных жилищных кредитов в 2020 году выступили Сбербанк, ВТБ и Россельхозбанк (таблица 1) [2].

Сложность и комплексность проблем ипотечного жилищного кредитования требует при их решении на государственном уровне использовать программный подход, предпринимать оперативные действия с учетом мирового опыта. В современных условиях существует необходимость одновременного стимулирования покупательской и инвестиционной активности на рынке жилья на государственном уровне.

Государство влияет на развитие ипотечного жилищного кредитование прямо (путем государственной поддержки массового жилищного строительства и покупки жилья) и косвенно (путем минимизации рисков ипотечного жилищного кредитования для субъектов ипотечного рынка).

Как участник и регулятор рынка ипотечного жилищного кредитования, государство действует на основании общих принципов, направленных на рост эффективности управления ипотечным кредитованием (рисунок 1).

Реализация вышеобозначенных принципов предполагает применение определенных инструментов формирования и развития рынка ипотечного жилищного кредитования. Механизм ипотечного жилищного кредитования включает в себя ряд аналитических и оперативных инструментов (рисунок 2).

Таблица 1. Топ-29 банков по выдаче ипотечных жилищных кредитов [составлено автором по материалам исследования]

\begin{tabular}{|c|c|c|c|c|c|}
\hline \multicolumn{2}{|c|}{ На 01.11.2020 г. } & \multicolumn{2}{|c|}{ На 01.10.2020 г. } & \multicolumn{2}{|c|}{ На 01.09.2020 г. } \\
\hline Банк & $\begin{array}{c}\text { Объем, } \\
\text { млн. руб. }\end{array}$ & Банк & $\begin{array}{l}\text { Объем, } \\
\text { млн. руб. }\end{array}$ & Банк & $\begin{array}{l}\text { Объем, } \\
\text { млн. руб. }\end{array}$ \\
\hline 1. Сбербанк & 1570400 & 1. Сбербанк & 1288384 & 1. Сбербанк & 1025868 \\
\hline 2. ВТБ & 730869 & 2. ВТБ & 631307 & 2. ВТБ & 541617 \\
\hline 3. Россельхозбанк & 128260 & 3. Россельхозбанк & 105407 & 3. Альфа-Банк & 90486 \\
\hline 4. Альфа-Банк & 123500 & 4. Альфа-Банк & 105342 & 4. Россельхозбанк & 83690 \\
\hline 5. ФК Открытие & 112839 & 5. ФК Открытие & 94692 & 5. ФК Открытие & 76537 \\
\hline 6. Газпромбанк & 96805 & 6. Газпромбанк & 85735 & 6. Газпромбанк & 74357 \\
\hline 7. Банк Дом.РФ & 84670 & 7. Росбанк & 70724 & 7. Росбанк & 59791 \\
\hline 8. Росбанк & 82562 & 8. Банк Дом.РФ & 69010 & 8. Банк Дом.РФ & 57260 \\
\hline 9. Промсвязьбанк & 77127 & 9. Промсвязьбанк & 66766 & 9. Промсвязьбанк & 56609 \\
\hline 10. Райффайзенбанк & 54643 & 10. Райффайзенбанк & 46944 & 10. Райффайзенбанк & 39531 \\
\hline 11. Абсолют Банк & 33050 & 11. Абсолют Банк & 28824 & 11. Абсолют Банк & 24318 \\
\hline 12. Уралсиб & 30583 & 12. Уралсиб & 25760 & 12. Уралсиб & 21224 \\
\hline 13. Совкомбанк & 29191 & 13. Совкомбанк & 24282 & 13. Совкомбанк & 19585 \\
\hline 14. Банк Санкт-Петербург & 28115 & 14. Банк Санкт-Петербург & 23303 & 14. Банк Санкт-Петербург & 18664 \\
\hline 15. АК БАРС & 22831 & 15. АК БАРС & 18985 & 15. АК БАРС & 15640 \\
\hline 16. ЮниКредит Банк & 19262 & 16. ЮниКредит Банк & 17053 & 16. Возрождение & 14885 \\
\hline 17. РНКБ & 15741 & 17. Возрождение & 15802 & 17. ЮниКредит Банк & 14468 \\
\hline 18. Транскапиталбанк & 13121 & 18. РНКБ & 13276 & 18. РНКБ & 10761 \\
\hline 19. Центр-инвест & 11674 & 19. Транскапиталбанк & 11540 & 19. Транскапиталбанк & 10315 \\
\hline 20. МКБ & 11388 & 20. Центр-инвест & 10074 & 20. Центр-инвест & 8213 \\
\hline 21. АТБ & 11298 & 21. МКБ & 9389 & 21. МКБ & 7601 \\
\hline 22. Металлинвестбанк & 9164 & 22. АТБ & 9205 & 22. АТБ & 7383 \\
\hline 23. МинБанк & 7676 & 23. Металлинвестбанк & 7282 & 23. Запсибкомбанк & 7054 \\
\hline 24. Запсибкомбанк & 7090 & 24. Запсибкомбанк & 7071 & 24. Металлинвестбанк & 5950 \\
\hline 25. СМП-банк & 5396 & 25. МинБанк & 5936 & 25. МинБанк & 4735 \\
\hline 26. Левобережный & 4909 & 26. СМП-банк & 4484 & 26. Левобережный & 3540 \\
\hline 27. Примсоцбанк & 4686 & 27. Левобережный & 4184 & 27. СМП-банк & 3439 \\
\hline 28. БЖФ & 3824 & 28. Примсоцбанк & 3985 & 28. Примсоцбанк & 3321 \\
\hline \multirow[t]{2}{*}{ 29. Кубань Кредит } & 3061 & 29. БЖФ & 3112 & 29. БЖФ & 2552 \\
\hline & & 30. Кубань Кредит & 2524 & 30. Кубань Кредит & 2155 \\
\hline
\end{tabular}




\begin{tabular}{|c|}
\hline \multicolumn{1}{|c|}{ Принципы } \\
росударства как \\
иплятора \\
ипочного рынка \\
•Наличие четкой \\
проработанной \\
законодательной \\
базы \\
•Эффективное \\
управление рисками \\
рынка Ижк \\
•Устойчивость к \\
системным рискам \\
•Обеспечение \\
прозрачности \\
ипотечного рынка и \\
его надежности
\end{tabular}

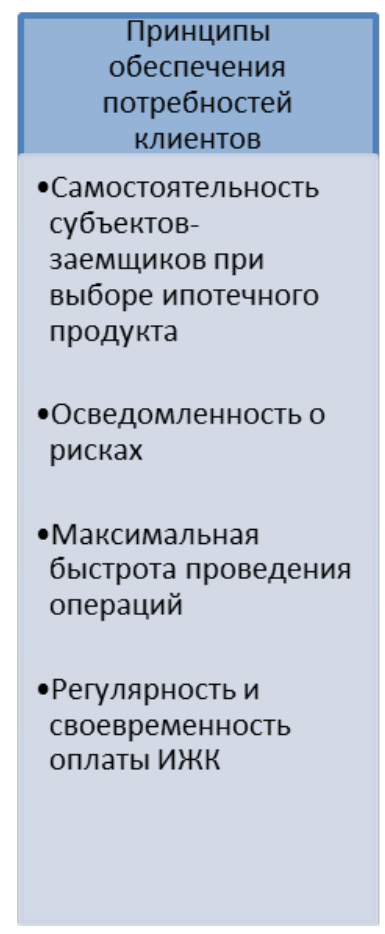

\begin{tabular}{|c|} 
Принципы \\
обеспечения \\
интересов всех \\
участников \\
•Транспарентность \\
процедур и правил \\
на ипотечном рынке \\
•Минимизация рисков \\
и эффективное \\
управление ими \\
•надежность, \\
безопасность и \\
доступность Ижк \\
•Технологичность, \\
удобство, скорость \\
выдачи и \\
обслуживаниям ижк \\
и эмитированных на \\
их основе ценных \\
бумаг \\
\hline
\end{tabular}

\section{Рисунок 1. Принципы рынка ипотечного жилищного кредитования}

[составлено автором по материалам исследования]

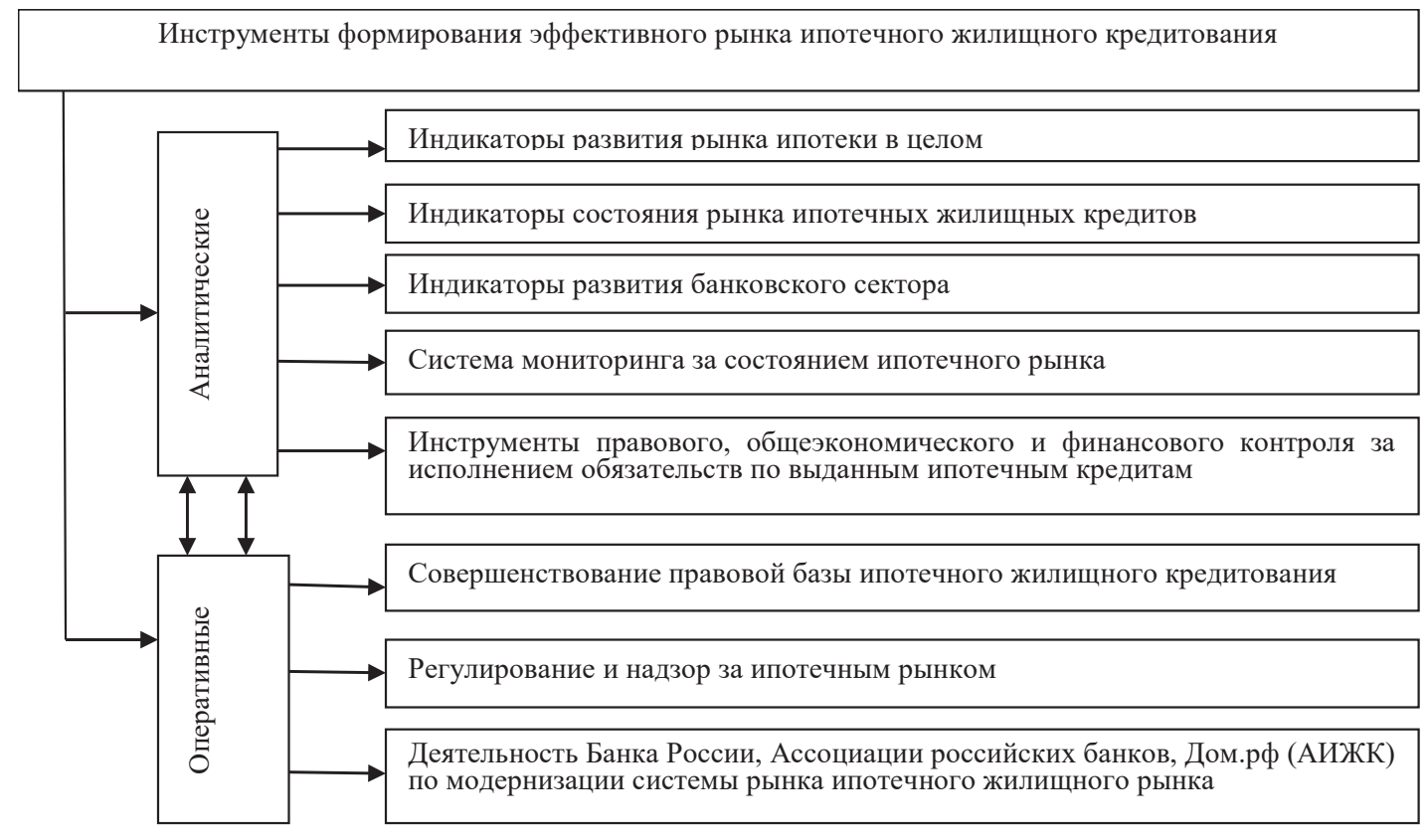

Рисунок 2. Инструменты формирования эффективного рынка ипотечного жилищного кредитования [составлено автором по материалам исследования] 
Среди последних можно назвать такие оперативные инструменты, как совершенствование правовой базы ипотечного жилищного кредитования, регулирование и надзор за ипотечным рынком, деятельность Банка России, Ассоциации российских банков, АИЖК (Агентство Дом. рф) по модернизации системы рынка ипотечного жилищного рынка.

K основным программам ипотечного жилищного кредитования 2020 г. можно отнести следующие:

1) Ипотека на новостройки под 6,5\%. Эта программа с господдержкой, запущенная в апреле по распоряжению президента РФ. По условиям программы кредит на квартиру в новостройке можно получить под 6,5\%. Максимальная сумма для жителей Москвы, Московской области, Санкт-Петербурга, Ленинградской области составляет 12 млн. рублей, для остальных регионов - 6 млн. рублей. [3] Официально программа называется «Господдержка 2020». Изначально ее называли «ипотека под 6,5\%», но вскоре это название потеряло свою актуальность: банки в борьбе за заемщика начали снижать процент по ипотеке. Так, банк ВТБ снизил ставку до 6,1\%, «Открытие»- до 5,99\%, «Дом.РФ»- до 5,9\% и т.д.

2) Семейная ипотека. Вторая по популярности банковская программа. По размеру процентной ставки $(4,7 \%)$ она даже выгоднее, чем льготная программа на новостройки (5,5\%$6,5 \%)$. На получение льготной ипотеки претендуют семьи с детьми: второй или последующий ребенок должен родиться с 1 января 2018-го по 31 декабря 2022 года. Сама программа действует до 1 марта 2023 года. Семьям, в которых есть ребенок с ограниченными возможностями, льготный кредит выдается до 31 декабря 2027 года. Требования к заемщикам стандартные, а именно: возраст - не менее 21 года, стаж работы - от года, при этом от 3 до 6 месяцев - на последнем месте работы.

3) Молодая семья. Эта государственная программа позволяет молодым семьям получить социальную выплату в размере 30-35\% стоимости жилья. В программе вправе участвовать молодые семьи, не имеющие собственного жилья. Наличие детей необязательно, но существует возрастной ценз для обоих супругов - не более
35 лет. На социальную выплату может претендовать и одинокий родитель, воспитывающий одного или нескольких детей. Деньги удастся потратить как на покупку квартиры в новостройке (приобретение дома), так и на строительство собственного жилья. Также можно использовать выплату в качестве первоначального взноса либо для погашения ипотечного кредита.

4) Ипотека для медицинских работников. Новая льготная программа, призванная поощрить медицинских сотрудников, работающих с COVID-19. У нее существуют жесткие временные ограничения - до 31 декабря 2020 года (если программа не будет продлена). Для получения ипотеки необходимо подтвердить статус медработника (стаж на последнем месте работы не менее трех месяцев). Из плюсов - этот вид ипотеки выдается на квартиры как в новостройках, так и на вторичном рынке, можно купить загородный дом и даже использовать для перекредитования. Минус состоит в том, что при первоначальном взносе от 10 до 20\% ставка составляет 8,6\% на первичном рынке, 9,2\% - на вторичном. Гораздо выгоднее ставка будет при первоначальном взносе от 30\%: в новостройке $-7,6 \%$, на вторичном рынке $-8,2 \%$. На приобретение дома ипотечный кредит возможно оформить, накопив как минимум 40\% для первоначального взноса - в этом случае ставка составит $10,2 \%$.

5) Дальневосточная ипотека. Ипотека с самыми низкими процентами - от 1,2 до $2 \%-$ имеет только один недостаток: приобрести жилье возможно только на территории Дальневосточного федерального округа. Ипотекой вправе воспользоваться супруги не старше 35 лет либо неполная семья, в которой возраст родителей не превышает 35 лет, а ребенка - 18 лет. Срок действия программы - до 31 декабря 2024-го. Объект - квартира в новостройке, жилой дом с земельным участком или земельный участок под строительство жилого дома на территории ДФО.

Таким образом, совершенствование системы ипотечного жилищного кредитования будет способствовать решению проблемы обеспечения населения жильем, что в свою очередь, позволит повысить устойчивость развития национальной экономики. 


\section{Библиографический список}

1. Официальный сайт AO «Дом.pф». URL: https://дом.pф (дата обращения 15.12.2020)

2. Ипотечное кредитование в цифрах. Статистика выдачи ипотечных кредитов URL: http://rusipoteka.ru/ ipoteka_v_rossii/ipoteka_statitiska/ (дата обращения 22.12.2020)

3. Гриценко М.А., Дроздова А.В. ИПОТЕЧНОЕ КРЕДИТОВАНИЕ: ТЕКУЩЕЕ СОСТОЯНИЕ И ПЕРСПЕКТИВЫ РАЗВИТИЯ В УСЛОВИЯХ ЭПИДЕМИИ КОРОНАВИРУСА // Экономика и бизнес: теория и практика. 2020. № 5-2. URL: https://cyberleninka.ru/article/n/ipotechnoe-kreditovanie-tekuschee-sostoyanie-i-perspektivy-razvitiyav-usloviyah-epidemii-koronavirusa (дата обращения: 26.12.2020). 